Transportation Research Forum

Safety and Security: Developing a Cooperative Process to Meet the Public Transportation Challenge Author(s): Kathryn Dobie and Rhonda L. Hensley

Source: Journal of the Transportation Research Forum, Vol. 44, No. 1 (Spring 2005), pp. 41-60

Published by: Transportation Research Forum

Stable URL: http://www.trforum.org/journal

The Transportation Research Forum, founded in 1958, is an independent, nonprofit organization of transportation professionals who conduct, use, and benefit from research. Its purpose is to provide an impartial meeting ground for carriers, shippers, government officials, consultants, university researchers, suppliers, and others seeking exchange of information and ideas related to both passenger and freight transportation. More information on the Transportation Research Forum can be found on the Web at www.trforum.org. 


\section{SAFETY AND SECURITY: DEVELOPING A COOPERATIVE PROCESS TO MEET THE PUBLIC TRANSPORTATION CHALLENGE}

Public transit systems are faced with a dual challenge in today's security-conscious operating environment. They must continue to monitor and respond to the needs of their riders by offering easy accessibility, on-time service, and adherence to the highest of safety standards. At the same time, public transit authorities must maintain a secure environment for passengers, their workforce, equipment and facilities. This presents a formidable challenge, especially for smaller transit entities with limited resources.

A method for determining rider perceptions of the safety and security policies of their transit provider is presented. This provides a method for the transit provider to determine rider perceptions and identify opportunities for enhancing rider awareness. The suggested process also provides transit personnel with a means for identifying gaps in their existing safety and security procedures, leading to the ability to improve their safety and security posture.

\section{by Kathryn Dobie and Rhonda L. Hensley}

The importance of quality in the provision of services has been the subject of numerous research efforts as service providers seek to understand: 1) how to determine customer needs and expectations, 2) what steps must be taken to meet those needs and expectations, and 3) how to ensure that customers recognize the service provider has responded appropriately with a service that meets their expressed needs and expectations (Parasuraman, Zeithaml and Berry, 1985; Brown and Swartz, 1989; Headley and Choi, 1992). Until this is accomplished, the provider will never achieve the level of customer satisfaction that leads to customer loyalty and provider competitive advantage. This endeavor alone presents a daunting challenge for public transportation providers.

Today, a second element has been added to the existing quality-of-service challenge; to provide increased levels of safety and security for customers, providers, and plant and equipment. The implementation of this requirement must be conducted in such a way as to ensure rigorous attention to detail and, simultaneously, to convey the message that safety and security are of utmost importance to the transportation provider. In a Bureau of Transportation Statistics (BTS) Survey, three out of four Americans indicated that they were concerned about the risk of terrorism against Americans traveling by highway, train, or public transit inside the United States (United States Department of Transportation 2002). The survey results highlight the fact that without user confidence in the ability of the public transportation provider to guarantee the highest levels of safety and security, transportation delivery quality, for instance, on-time service, becomes a moot issue.

Prior to 2003, the traveling public could access key government information and statistics regarding the safety and security of the various modes of transportation available at the websites of the U.S. Bureau of Transportation Statistics (http://www.bts.gov/). If a present or potential customer chose to do so, they could use this information for making travel decisions and/or initiating efforts to make changes to the existing safety or security procedures being used by transit entities of concern. Specific information regarding individual transportation entities is now denied because of rules adopted by the Transportation Security Administration following the signing of the Homeland Security Act Nov. 25, 2002 (Schmitt and Pound 2003, p.20). While the rationale for the implementation of these rules is to either prevent or inhibit the collection of information that might be of use for terrorist activities against public transportation 
providers, it also eliminates the ability of users to scrutinize safety and security data in an effort to evaluate their personal safety and security when using a particular transportation provider and/or working to effect improvements. Just as importantly, it also removes the transparency of safety and security initiatives designed to protect the traveling public. Documented results of these initiatives form the basis for judgments regarding their effectiveness by concerned users. It has been said that information is power. Limiting access to information creates an underlying suspicion that things are not as they should be.

Without the ability to provide specific measurable information, public transportation providers must develop other methods to convey to users that their safety and security are important. To understand what information must be made available to riders, public transit companies must first understand the level of understanding riders have regarding the safety and security of public transit. Once this information is gathered and analyzed, public transit companies can make plans to increase rider awareness where needed.

The objective of this study is the development of a collaborative process by which public transportation administrators, users, and operators identify security enhancement opportunities and implement security enhancement programs. This process integrates the efforts and concerns of all parties, creating a transparency intended to synchronize stakeholder perceptions of, and confidence in, the outcomes of the implemented initiatives.

The paper is organized as follows. Research related to the use of collaborative processes and Six Sigma processes are presented followed by the development of the conceptual framework on which the study is based. The study methodology, including details about the study setting and the survey development process, is presented. The analysis of the survey results is presented and conclusions and recommendations, based on the results, are developed.

\section{LITERATURE REVIEW}

Research has examined the issue of process improvement and identified methods to implement those improvements (Hoerl and Snee,
2002). Leadership and the involvement of people were considered to be the two critical elements of success when planning and implementing process improvement (Larson and Haversjo, 2000). Those conclusions are supported by the results of a study by Sebastianelli and Tamimi (2003) which identified the constructs that were necessary for the successful implementation of change initiatives. Four of the constructs, human development, planning, leadership, and resources, were firm focused, and the fifth construct, customer orientation, clearly emphasizes the need to include customer concerns when implementing change. In fact, the overall results of service-quality research highlight the importance of meeting customer requirements to ensure service quality (Wycoff, 1984).

Collaboration is a means of arriving at a solution that satisfies all parties involved in the process (Thomas, 1992; Esper and Williams, 2003). Collaborative processes are especially applicable in this setting because changes will be based on the perceptions of the users of the public transit system and depend on the support and cooperation of employees (Straus, 2002). Customer relationship management (CRM), and supplier relationship management (SRM) provide examples of the importance of developing the collaborative mindset and communication needed to effectively identify and implement solutions for current and future improvement efforts. The emphasis in CRM research has been on identifying and providing solutions to meet customer needs (Day, 2003). This includes determining customer buying patterns (Peppers and Rogers, 1993; Kelly, 1997; Deighton, 1998; and Seybold, 2001) and providing an emphasis on product/service performance (Crosby and Johnson, 2000). SRM focuses on the development of relationships for the purpose of improving coordination leading to improved operational efficiency (Fisher, 1997). The preponderance of research in SRM focuses on the development and maintenance of the relationships necessary to support managerial initiatives (Cannon and Perrault, 1999). Both CRM and SRM illustrate the importance of participatory input to ensure cooperation by both the customer, or transit user, and the public transit management and operational personnel who provide the desired level of service. 
Six Sigma is one of several quality improvement programs widely used by businesses (Hoerl and Snee, 2002). Some programs, such as benchmarking and reengineering, are more narrowly focused than Six Sigma. Total Quality Management has a broader focus, but Six Sigma seems to capture the customer orientation needed in this study's situation (Taghaboni-Dutta and Moreland, 2004). DMAIC is an accepted approach for Six Sigma implementation. There are five steps in the DMAIC process: (1) Define the problem and select the process targeted for improvement; (2) Measure the current process by collecting quantifiable data both from within the organization and from customers; (3) Analyze the data using statistical methods where appropriate to produce a baseline measure of performance; (4) Improve the process using the data gathered from the process as a basis; and (5) Control the process by setting up a system to help standardize the changes (Harry and Schroeder, 2000; Benedetto, 2002; Hoerl and Snee, 2002).

Although Six Sigma has its roots in manufacturing it has been successfully used in service settings. Some common problems faced by service organizations using Six Sigma include difficulty in gathering hard data to be analyzed and the difficulty of measuring customer satisfaction (Benedetto, 2002).

\section{CONCEPTUAL FRAMEWORK}

Based on research on the use of collaborative processes in organizations, it was determined that a method having a strong customer orientation was needed to address the issue of customer awareness of safety and security efforts. Six Sigma was chosen as the vehicle for the building of a collaborative process primarily because of its strong reliance on a customer orientation. It was further decided that the DMAIC process was the best means of presenting this method to the organization.

This research follows the organization through the first three steps of the DMAIC process and then offers suggestions regarding implementation that the public transit company could then undertake. It is expected that as a result of using the Six Sigma process, public transportation administrators, users, and operators will develop a common understanding of what changes are being made to increase security and safety, why these changes are needed, and what results are expected as a result of these changes.

There are many different public transportation alternatives available to the traveling public including passenger rail, passenger oriented water transport (ferry), underground systems (MARTA, BART), and motor coach (both tourism oriented and urban transit systems). The general process developed in this study is applicable to different public transport modes, but the specifics should be tailored to the individual mode and situation.

\section{METHODOLOGY}

\section{Research Setting}

This particular study targeted mid-sized motorcoach-based urban public transit systems. Systems of this size are not included in the 50 largest which have received the attention of the Department of Transportation security initiatives. They have the same responsibilities for public safety and security as larger transit systems, but do not receive the same levels of funding and training. Therefore it is their responsibility to develop their own internal process to continuously improve their safety and security programs.

\section{Survey Development}

Before instituting change, in this case the establishment of a collaborative process to identify safety and security enhancement opportunities, it is essential to determine current administrator, driver, and rider perceptions of the existing security and safety programs. This will provide a benchmark against which the results generated by changes that might later be instituted can be measured.

The most productive way to determine the current status is to question administrators, drivers, and riders, and review existing measurement documentation. Common methods of obtaining administrator, driver, and rider input include 
the use of surveys, focus groups and personal interviews.

Transit Director Input. In this study, a survey instrument and interviews were used to assess and compare the state of safety and security in four urban transit companies located in North Carolina (Appendix 1). The purpose was to be able to first document, and then compare the processes and practices of transit companies of a similar size in the same geographic region. Results of the interviews and surveys were used to develop the initial surveys for riders and drivers. Rider and driver surveys were then reviewed by the resource transit director, with their suggestions being incorporated into the final surveys.

The completion of the survey instrument by the individual transit directors was accomplished through the use of phone and fax communication. The directors were initially contacted by phone and the project and objectives explained. After securing their agreement to participate in the study, the survey was then faxed to them to be completed and returned by fax. It must be noted that one transit agency declined to participate in the study on the advice of their attorney. They were concerned that their participation might conflict with security directives from the Transportation Security Administration.

The first set of survey questions was designed to establish what safety procedures were currently in place at the individual public transit entities. The importance of this information is to provide a picture of what is "on-the-books" and where the emphasis for use or enforcement is actually placed. The responses received in this study indicated that the different transit companies utilized safety and security technologies such as cameras on the bus and around the transit facilities, and made use of employee ID systems. The systems differed in the use of private security companies. Two of the transit systems surveyed used third-party security companies while two others did not. Surprisingly, two of the four transit companies reported placing only some-to-slight emphasis on procedures manuals and security standards or goals (Table 1). This finding underscores the importance of instituting safety and security procedures in a time when the previous assumption that safety and security were a given has been drastically changed.

Record maintenance is an important method for tracking safety and security measures, establishing a benchmark, and documenting the results of efforts to improve the status quo. From the responses received, it is evident that record keeping is considered to be an important activity, perhaps because of governmental reporting requirements and protection against lawsuits. The use of those records varied among the transit systems surveyed. All the transit companies used the records as a basis for making changes in existing procedures. Two of the transit companies also used the records to track trends; and two of the companies used the records for tracking trends and developing new procedures (Table 1).

The final set of questions on the directors' survey targeted the driver-hiring process. Some of these procedures, such as physical and drug testing and performing background checks, are federally mandated and all respondents were in compliance. All respondents indicated that initial post-hire training was a part of the hiring process and $67 \%$ indicated that periodic post-hire training beyond the initial training was required.

In the personal interviews held with the human resource transit director, a number of safety/security devices were discussed. The use of various safety/security devices was not uniform across all systems. For example, newer buses might have different safety and security devices than an older bus. The list of safety/security devices included the use of video cameras in the buses and on the grounds, telecommunications equipment on the buses that allow the driver to contact headquarters or the police, security guards on the grounds and on the buses, and lockdowns on the maintenance shop and bus storage areas to prevent unauthorized access.

Rider Surveys. Once the survey was finalized, administration to the riders was conducted over a two week period (Appendix B). The cooperation of the transit director and the individual route drivers were important factors contributing to the success of this effort. Student teams consisting of transportation majors were 
Table 1: Director's Input - Emphasis on Procedures Manual and Established Security Standards or Goals and Usage of Records

\begin{tabular}{|c|c|c|c|c|c|c|c|}
\hline & \multirow{2}{*}{$\begin{array}{c}\text { Emphasis } \\
\text { Placed on } \\
\text { Procedures } \\
\text { Manual }\end{array}$} & \multirow{2}{*}{$\begin{array}{c}\text { Emphasis on } \\
\text { Established } \\
\text { Security } \\
\text { Standards or } \\
\text { Goals }\end{array}$} & \multirow[b]{2}{*}{ Usage of Records } & \multicolumn{4}{|c|}{ Records } \\
\hline & & & & $\begin{array}{l}\text { Incident } \\
\text { Reports }\end{array}$ & Accidents & Injuries & $\begin{array}{c}\text { Cost of } \\
\text { Accidents }\end{array}$ \\
\hline Much & 2 & 2 & $\begin{array}{c}\text { Changes in } \\
\text { Existing } \\
\text { Procedures }\end{array}$ & 1 & 1 & 1 & 1 \\
\hline Some & 1 & 1 & + Track Trends & 0 & 0 & 1 & 1 \\
\hline Average & 0 & 1 & $\begin{array}{l}+ \text { Development of } \\
\text { New Procedures }\end{array}$ & 1 & 1 & 0 & 0 \\
\hline Slight & 1 & 0 & & & & & \\
\hline None & 0 & 0 & & & & & \\
\hline
\end{tabular}

trained in the survey administration process. The students were provided with a "script" to be used in approaching riders. The transit company provided free bus passes that were given to the participants upon completion of the survey. The students rode different bus routes at different times of the day, administering the surveys to the bus patrons.

A total of 276 surveys were collected and used in the analysis. Some of the surveys were partially answered and were used in the statistical analysis when possible. Non-respondents are indicated in the tables as "Not Answered."

The demographic characteristics of the riders indicated that bus riders were fairly evenly divided between male and female patrons and there was a well-distributed representation of age groupings. Those surveyed indicated that the public transit system was used for a variety of reasons with $39 \%$ (105 of the 271 answering the question) indicating that they use the bus for more than one reason (Table 2). A total of $27 \%$ of the riders indicated that they only use the bus to go to work (72 out of 271 answering the question). Other reasons cited (in order from most frequently mentioned to least frequently mentioned) include social, shopping, school, and doctor's appointments.

The majority $(65 \%)$ of the surveyed riders (177 out of 274 who answered the survey) indicated that they use the bus between one to seven times per week. Only $26 \%$ of the riders (71 out of 271 who answered the survey) are planning to increase their usage of the bus. Most of the riders (74\%) predict that their usage will remain the same or decrease.
Table 2: Rider Survey - General Information

\begin{tabular}{|c|c|}
\hline \multicolumn{2}{|c|}{ Gender } \\
\hline Female & 143 \\
\hline Male & 129 \\
\hline Not Answered & 4 \\
\hline \multicolumn{2}{|c|}{ Age Range } \\
\hline Under 21 & 50 \\
\hline $22 \quad 30$ & 78 \\
\hline 3145 & 78 \\
\hline $46 \quad 60$ & 53 \\
\hline Over 60 & 12 \\
\hline Not Answered & 5 \\
\hline \multicolumn{2}{|c|}{ Purpose for Riding } \\
\hline More than One Reason & 105 \\
\hline Work & 72 \\
\hline Social & 38 \\
\hline Shopping & 31 \\
\hline School & 21 \\
\hline Doctor & 4 \\
\hline Not Answered & 5 \\
\hline \multicolumn{2}{|c|}{ Current Usage } \\
\hline 1 to 4 & 90 \\
\hline 5 to 7 & 87 \\
\hline 8 to 14 & 53 \\
\hline 15 or more & 44 \\
\hline Not Answered & 2 \\
\hline \multicolumn{2}{|c|}{ Predicted Future Usage } \\
\hline Decrease & 85 \\
\hline Stay Same & 115 \\
\hline Increase & 71 \\
\hline Not Answered & 2 \\
\hline
\end{tabular}


Driver Surveys. The driver surveys were administered by the safety director in one of their regular monthly meetings (Appendix C). Without the cooperation of the transit director and the director of safety, this part of the project could not have been completed. The safety director was given an information sheet to read to the drivers explaining the purpose of the survey. The completed surveys were placed in a sealed box which was then picked up by the researchers.

A total of 87 surveys were collected. Some of the surveys were partially answered and were used in the statistical analysis when possible. Non-respondents are indicated in the tables as "Not Answered."

\section{RESULTS}

The first two steps of the Six Sigma DMAIC process were encompassed in the development and gathering of data from the surveys. The third step of the DMAIC process is to analyze the data to develop a baseline understanding of performance related to public awareness of safety and security measures.

\section{Customer Awareness of Safety and Security Measures}

Riders were asked to identify both safety and security devices. Of the 276 people who completed the survey $24 \%$ (65 out of 276 ) chose not to answer either question (Table 3). In answer to the question about identification of safety devices, a total of 46 riders were unable to identify any safety devices, while 52\% (109 out of 211 who answered the question) of the riders answering the question could identify no more than one safety device. Even fewer could identify security devices, as $85 \%$ (180 out of 211 who answered the question) could identify no more than one security device.

This finding was especially surprising because the survey instrument was administered while the respondent was riding the bus and could easily look around to see what safety and security items were in view. One might assume that those who used the transit system on a fairly regular basis would be more likely to be aware of the safety and security measures that were in place on the motor coach itself and in the bus stop
Table 3: Rider Survey - Number of Safety and Security Devices Identified

\begin{tabular}{|l|c|}
\hline \multicolumn{2}{|c|}{ Number of Security Devices } \\
\hline 0 & 79 \\
\hline 1 & 101 \\
\hline 2 & 21 \\
\hline 3 & 8 \\
\hline 4 & 2 \\
\hline Not Answered & 65 \\
\hline \multicolumn{2}{|c|}{ Number of Safety Devices } \\
\hline 0 & 46 \\
\hline 1 & 109 \\
\hline 2 & 40 \\
\hline 3 & 16 \\
\hline Not Answered & 65 \\
\hline
\end{tabular}

area. Using this assumption, it would be easy for those who were charged with the responsibility for implementing safety and security programs, procedures, and equipment, to overlook the necessity for creating awareness among those who are frequent bus patrons. From the results of the survey, it is evident that the assumption of rider awareness of safety and security devices is not valid.

\section{Driver Awareness of Safety and Security Measures and On-Going Training}

The driver survey focused on the training and responsibilities of the driver in the areas of safety and security. Few of the drivers (only two out of a total of 86 drivers answering the question) were not aware of the existence of the policies and procedures manual (Table 4). A slightly higher percentage, $17 \%$ (14 out of 81 answering the question) were unfamiliar with the contents of the policies and procedures manual, while $29 \%$ of the drivers ( 25 out of 85 who answered the question) reported that the policy and procedures manual was not a part of their initial training.

The drivers were also asked about ongoing training and its frequency. While 70 of the drivers reported participating in an on-going training program, only 54 reported that the ongoing training was held at least monthly (Table 5). This is interesting because the surveys were administered at the monthly training meeting and 87 completed surveys were returned. 
Safety and Security

Table 4: Driver Survey - Policy and

Procedures Manual

\begin{tabular}{|l|c|}
\hline \multicolumn{2}{|c|}{ Awareness } \\
\hline No & 2 \\
\hline Yes & 80 \\
\hline Do Not Know & 4 \\
\hline Not Answered & 1 \\
\hline \multicolumn{2}{|c|}{ Content Familiarity } \\
\hline No & 14 \\
\hline Yes & 68 \\
\hline Not Answered & 5 \\
\hline \multicolumn{2}{|c|}{ Part of Initial Training } \\
\hline No & 25 \\
\hline Yes & 61 \\
\hline Not Answered & 1 \\
\hline
\end{tabular}

When asked about the safety procedures that the individual driver was responsible for performing, 57\% (47 out of 83 drivers answering the question) reported that they were responsible for conducting a pre-shift equipment check, incident prevention, and operating the bus according to safety requirements. The other $43 \%$ of responding drivers reported that they were responsible for one or two of these functions, but not all three (Table 6).

When drivers were asked to indicate what security procedures they were responsible for performing, the results were similar to those regarding safety procedure performance. In this case, $63 \%$ of the drivers (52 out of 83 answering the question) reported performing all of the indicated procedures; awareness and reporting of unusual activities, inspecting the inside and outside of the vehicle, and making sure the vehicle was in a secured location while unattended. The remaining drivers (37\%) reported performing one or more of these functions but not all of them (Table 6).

\section{Differences in Perceptions}

The results of the surveys were tabulated and analyzed using SPSS. There were multiple objectives for the statistical examination. The primary objectives were: 1) to determine administrator, driver and rider perceptions of the current safety and security measures, 2) to identify any differences in perceptions between
Table 5: Driver Survey - Ongoing Training

\begin{tabular}{|l|c|}
\hline \multicolumn{2}{|c|}{ Participation in On-Going Training } \\
\hline No & 14 \\
\hline Yes & 70 \\
\hline Not Answered & 3 \\
\hline \multicolumn{2}{|c|}{ Frequency of On-Going Training } \\
\hline Daily & 0 \\
\hline Weekly & 0 \\
\hline Monthly & 54 \\
\hline Other & 18 \\
\hline Not Answered & 15 \\
\hline
\end{tabular}

the groups, and 3) to identify weaknesses and strengths in the current safety and security programs.

Identify current safety and security measures. The first objective is to establish the status of current safety and security measures as seen by the individual administrators, drivers and riders. This provides benchmarks for measuring the results of any changes made as a result of this effort. Because riders, drivers, and directors view these measures from a different perspective, it is conceivable that they also have different views regarding their effectiveness and usefulness. It is important to establish the existence of any common perceptions as well as any differences.

Identify differences. The second objective is to identify the differences in perceptions between the stakeholder groups. This allows directors to reexamine the effectiveness of current programs and determine if they are performing as intended. If riders or drivers indicate that the current programs are not performing as intended, it signals the need either for redesign or for increased emphasis on implementation procedures and training. If the programs are effective and performing as intended but one or more stakeholder groups indicate that they don't agree, it may signal the need for an education initiative to inform and/or demonstrate to other stakeholder groups the safety and security benefits they are receiving as a result of these programs.

Marketing has made use of "gap analysis" to measure customer satisfaction with service 
Table 6: Driver Survey - Safety and Security Procedures Performed by Driver

\begin{tabular}{|l|c|}
\hline \multicolumn{2}{|c|}{ Safety Procedure Performed } \\
\hline Pre shift equipment check & 2 \\
\hline Incident prevention & 2 \\
\hline Operate bus according to safety requirements & 14 \\
\hline Pre shift equipment check \& Incident prevention & 1 \\
\hline $\begin{array}{l}\text { Pre shift equipment check \& Operate bus according to safety } \\
\text { requirements }\end{array}$ & 13 \\
\hline Incident prevention \& Operate bus according to safety requirements & 4 \\
\hline $\begin{array}{l}\text { Pre shift equipment check \& Incident prevention \& Operate bus } \\
\text { according to safety requirements }\end{array}$ & 47 \\
\hline Unanswered & 4 \\
\hline \begin{tabular}{l} 
Security Procedure Performed \\
and outside of vehicle \& Making sure vehicle is in secured location \\
while unattended \\
\hline Unahicle is in secured location while unattended \\
secured location while unattended
\end{tabular} & 4 \\
\hline and outside of vehicle & 2 \\
\hline Awareness and reporting of unusual activities & 6 \\
\hline Inspecting inside and outside of vehicle & 4 \\
\hline Making sure vehicle is in secured location while unattended & 2 \\
\hline Awareness and reporting of unusual activities \& Inspecting inside & 2 \\
\hline
\end{tabular}

quality (Parasuraman, Zeithaml and Berry 1985; Brown and Swartz 1989). In this process, the differences between the perceptions of the service provider and the service recipient are measured. The results are used as a basis for change in the service elements themselves, the delivery methods, or the marketing of the service and the expected outcome. The objective is to reach a mutual understanding of service composition, delivery, and outcome (Normann and Ramirez 1993; Candido and Morris, 2000). Using this same principle, a statistical examination of the results of the surveys (Headley and Choi, 1992) can be used to provide an understanding of the differences in the perceptions of the providers and users of public transportation, providing a roadmap for realignment and the synchronization of provider and user perceptions.
A statistical comparison of the responses provided by the riders and the drivers in this study indicated that there were significant differences between the perceptions of the two groups. Riders were asked to indicate their level of concern regarding their safety while using the transit system. On a scale of 1 to 5, with lindicating the highest level of concern, respondents indicated that they were only somewhat concerned (mean of 2.486). When drivers were asked how they would rate the level of safety, they indicated that they considered the level of safety to be above average, mean of 3.897 on a 5 point scale with 5 indicating the highest level. A two-tailed ttest of the responses indicated that the differences were significant with $\mathrm{p}=1.31 \mathrm{E}-17$ (Table 7). An examination of the responses to the questions regarding security produced similar re- 
Safety and Security

Table 7: Differences in Safety and Security Concerns - Analysis of Variance Results (Bolded p-values are Significant)

\begin{tabular}{|c|c|c|c|c|c|c|}
\hline & & Mean & $\begin{array}{c}\text { Standard } \\
\text { Deviation }\end{array}$ & N & t-stat & p-value \\
\hline \multirow{2}{*}{$\begin{array}{c}\text { Differences in Safety Concerns } \\
\text { Rider Survey Safety Concerns } \\
\text { Driver Survey Rating for Safety Level }\end{array}$} & Rider & 2.486 & 1.349 & 276 & 8.9998 & $\mathbf{1 . 3 1 E - 1 7}$ \\
\cline { 2 - 8 } & Driver & 3.897 & 1.000 & 86 & & \\
\hline $\begin{array}{c}\text { Differences in Security Concerns } \\
\text { Rider Survey Security Concerns } \\
\text { Driver Survey Rating for Security Level }\end{array}$ & Rider & 2.599 & 1.393 & 274 & 5.0082 & $\mathbf{8 . 6 4 3 E - 0 7}$ \\
\cline { 2 - 8 } & Driver & 3.407 & .975 & 86 & & \\
\hline $\begin{array}{c}\text { Differences in Safety Concerns } \\
\text { Rider Survey Driver's Safety Concern } \\
\text { Driver Survey Rating for Safety Level }\end{array}$ & Rider & 3.978 & 1.066 & 270 & 0.5440 & 0.5868 \\
\cline { 2 - 8 } & Driver & 3.897 & 1.001 & 86 & & \\
\hline $\begin{array}{c}\text { Differences in Security Concerns } \\
\text { Rider Survey Driver's Security Concern } \\
\text { Driver Survey Rating for Security Level }\end{array}$ & Rider & 3.933 & 1.050 & 270 & 4.1162 & $\mathbf{4 . 8 E - 0 5}$ \\
\cline { 2 - 8 } & Driver & 3.407 & .975 & 86 & & \\
\hline
\end{tabular}

sults. Riders indicated that they were somewhat concerned, mean of $2.599(1=$ high to $5=$ low $)$, while drivers indicated that they regarded the level of security to be adequate, mean of 3.407 $(1=$ low to $5=$ high $)$. The two-tailed t-test indicated that the differences in perspective were significant with a $\mathrm{p}=8.64 \mathrm{E}-07$ (Table 7).

Drivers also perceived the level of safety to be fairly high with a mean of 3.897 on a 5 point scale where 1 indicates the highest level of concern that the level of safety is inadequate. When riders were asked whether they believed that the driver felt that their safety was at risk, results indicated that riders perceived that the driver was satisfied with the level of safety with a mean of 3.978 on a 5 point scale where 1 indicates the highest level of concern. A two-tailed t-test to determine if there were significant differences in their perceptions indicated that there were no significant differences with $\mathrm{p}=.5868$ (Table 7).

When asked whether they thought that the driver was concerned with their security, riders indicated that drivers were only somewhat concerned with their security, with a mean of 3.933 on a 5-point scale where 1 indicated the highest level of concern. Drivers indicated that the level of security was somewhat adequate with a mean of 3.407 on a five point scale with 5 indicating the highest level of security. A two-tailed t-test of the responses indicated a significant difference in the perceptions of riders and drivers with a $\mathrm{p}$ score of 4.8E-05 (Table 7).

\section{DISCUSSION}

The results raise a number of questions and lead to a number of interesting conclusions. First, as the transit director survey/interviews show, even relatively small urban transit systems are collecting data from day-to-day operations, analyzing the data and using it in a number of different ways. This study focused on data that might identify safety and security problems such as incident reports, accident reports, injury reports and whether a cost figure was placed on accidents. All transit companies used the data as a basis for making changes in procedures. The data was also used to track trends and to create new procedures. These are the kinds of data that typically are collected and used in Six Sigma analysis.

A second interesting finding from the surveys/interviews with the directors was that they feel that the policy and procedures manual and established security standards are emphasized. This finding is not supported by the data from the driver survey that showed that the drivers, although aware of the policy and procedures manual, were largely unfamiliar with its contents and were not aware of its use as part of their initial job training. This finding suggests that 
more emphasis needs to be placed on making the drivers aware of the policy and procedures manual and its contents. Perhaps one way to encourage this is to use the policy and procedures manual as part of the monthly driver meetings in a mini-training session.

Based on the driver's survey, more on-going training needs to take place. Becaue of union regulations, meetings with the drivers are held no more often than once per month. Data on attendance needs to be collected and an effort needs to be made to ensure that each driver participates in on-going training. Incorporating mini-training sessions that focus on small issues of safety and security could be used in each driver's meeting.

The driver's survey regarding the safety and security procedures performed each shift identified a number of instances in which drivers claimed not to perform all the checks required by the transit company. This needs to be investigated and if the problem is real (not just confused drivers answering the survey) drivers need to receive training in these required procedures. The transit company might make use of a check sheet with procedures listed that each driver fills out during each shift to remind them of the proper procedures and to be used as a check.

Based on the results of the rider survey analysis, it is clear that riders are not aware of the transit company's efforts to provide a high level of safety and security in and around the vehicle. Riders probably rely on general feelings about how safe and secure they feel when riding the bus. The transit company could undertake a program to educate the riders on current safety and security devices and procedures and provide new information when additional features are added. A simple program using posters displayed in the waiting areas and on the buses might be effective.

It is also clear that the riders feel more concerned about safety and security than do the drivers. In addition, results suggest that the riders also feel that the drivers are not as concerned with safety and security as the riders. This finding is important because it is easy to look at issues from within the organization and think everything is okay. This finding could be used as a training tool to convince drivers of the importance of making their regard for safety and security highly visible to riders.

\section{RECOMMENDATIONS}

The data analysis for this particular transit company has identified several areas in which process improvements can be made. Specific recommendations have been developed that could then be used in the Six Sigma process.

\section{Improve Rider Awareness of Safety and Security Efforts}

The first recommendation is that the company develop a program to increase customer recognition of the safety and security efforts already in place. The data analysis clearly showed that there was a disconnect between the actual safety and security measures used at the company and what riders noticed. This program could be as simple as creation of a series of posters to be used both in the bus and in the station waiting area to tell riders of some safety and security measures being used. When new buses arrive, the same posters could be used to let riders know of the improved safety and security measures.

\section{Improve Driver Training}

Transit companies should also work on improving the safety and security training offered to drivers. The data analysis identified a number of areas for concern. It appeared that the drivers were, at best, offered monthly on-going training and some drivers seemed unaware of these training sessions. In addition, some drivers were unfamiliar with the contents of the policy and procedures manual, and not all drivers followed the same safety and security procedures in operation of the buses. Training efforts in safety and security need to be increased and the transit company must ensure that all drivers are getting the training. The use of materials available from the Federal Transit Administration such as the "Top 20 Security Program Action Items for Transit Agencies," (http://transit-safety.volpe.dot.gov/ security/SecurityInitiatives/Top20/default.asp (accessed 9/29/2004) and the "Employee Guide to System Security - Bus Operations" 
(http://transit-safety.volpe.dot.gov/Security/ SecurityInitiatives/EmployeeGuide/ BUS/ (accessed 9/29/2004) would provide helpful information for the training director.

The transit company should also attempt to establish benchmarks for safety and security operations by communication with other transit companies to learn what they are doing.

\section{Apply the DMAIC Process}

Six Sigma's DMAIC process can be used by transit companies to uncover process problems and provide a structure for identifying solutions and implementing those solutions in the organization. In general, the steps could be used as follows:

(1) Define the Problem. The first step is one of process problem identification. Processes should be examined to identify their strengths and weaknesses. In this particular instance, the company was concerned with identification of strengths and weaknesses in their current safety and security programs. The identification process reveals the possibility of new initiatives to strengthen the position of existing strengths and to eliminate weaknesses. The process provides a starting point for identifying the security enhancement opportunities available to the individual transit entity so that security enhancement programs may be designed and implemented.

(2) Measure the Current Process. The identification of strengths and weaknesses can be accomplished through individual interviews, focus groups and by the inclusion of specific questions in the survey instrument. For example, driver perceptions of the safety level (mean of 3.897) and security level (mean 3.407) on a 5point scale where 5 represented a rating of "very high" indicate that there is room for improvement in this area. These, and other specific questions that are targeted to the particular situation and group, can prove most useful when identifying opportunities for safety and security enhancement programs and activities.

(3) Analyze Data and Propose Changes. Once the strengths, weakness, and perceptual differences are identified, it is important to obtain an understanding of their root causes. If the time and effort to do so is not invested in the project, it is quite possible that symptoms of weaknesses rather than causes will be addressed. This may appear to provide a "quick fix," but will not resolve a problem which will manifest itself in another symptom. In the case of strengths, identifying the factors that contribute to that strength will perhaps provide guidance for strengthening weaknesses or even reveal ways in which an existing strength can be reinforced. Perceptions of strengths and weaknesses depend on the perspective of the observer. This is why it is so important to determine the perspective of all parties, in this case, riders, drivers and administrators, to get a complete picture. This broad view should help the transit company identify and focus its efforts on those gaps that pose real threats to safety and security. Improperly identifying and/or failing to identify gaps in safety and security are both causes for concern and lead to misdirected efforts by any or all of the affected stakeholders.

Many corporate entities have adopted the use of Six Sigma as a method of promoting continuous improvement in their operating processes. The techniques, or tools, are easy to use and provide users with methods for achieving their improvement goals. Tools that enable the visual representation of processes and all the elements that constitute that process make it more readily apparent where errors or omissions are most likely to occur. It also makes it easier to identify where time and effort is being spent on activities that do not contribute to the accomplishment of the goal. Two particularly useful tools for making the elements of the process and their sequencing visible are the process map, or flowchart of the process, and the cause and effect, or fishbone, diagram.

The use of the process visualization tools should result in the identification of activities that need to be changed to make the current program more effective and activities that might need to be eliminated because they do not contribute to the accomplishment of safety and security goals, and/or of processes that need to be redesigned or added in order to meet the safety and security needs of the stakeholders. The success of this phase depends on the ability of the participants to creatively approach the task. A commonly used and effective method of generating a pool of ideas is brainstorming.

During the brainstorming process, every effort must be made to encourage the genera- 
tion of ideas. The task of sorting through and organizing those ideas comes later. The objective at this stage is to encourage creative ideas for improvement. This is not an easy task as power and politics must be set aside so that the free flow of ideas can occur. When participants become comfortable with the idea that no idea will be criticized and non-traditional approaches to the task under consideration are welcome, the level of creativity and innovative thinking will rise exponentially.

Once the idea-generation phase is completed, the next task is to organize the ideas into a workable format. As a part of this phase, ideas may be discarded, combined or refined as the participants desire. Ideas must also be prioritized. The criteria used to prioritize improvement projects that have been generated through the brainstorming process may be based on urgency of the projected improvement, time to completion, costs, or some other criteria which is critical for the particular public transit entity. Whatever the criteria used, projects stemming from the ideas that are selected from the brainstorming pool should be organized in a workable order and team assignments, responsibilities, and authority delineated.

The results of the survey of directors indicated that the most common measures used in the urban transit setting were related to incidents occurring on the bus or close proximity and the number of accidents and their related injuries and costs. Maintenance records were primarily used to track routine maintenance schedules. One starting point in developing process improvement would be to assign teams to determine what their objectives are and what measures would most appropriately be used to determine if the objectives are being met. A first step in this process might be to review current performance measurements and determine if they are adequate for the task at hand. In most cases the general measurements in use are not targeted enough to adequately measure project success. The measures must be quantifiable, intuitive, and easy to record. The design of a simple recordkeeping format is appropriate at this time. The generation, maintenance, and review of these documents must be an integrated part of normal management and periodic review processes.
(4) Improve the Process. Implementing change can be the most challenging part of the process. To initiate the project requires visible support from upper management and a clear timeline (the use of Gantt charts is helpful here) of when the various tasks are to be started and completed. With managerial support and the timeline in place, it is essential to inform everyone involved in or affected by the change as to what to expect and what it will take to accomplish the change. They must also be aware of their role in the change process. This includes the reassurance that any needed skills will be gained through training opportunities. Most importantly, they need to understand the benefits that will accrue to them and everyone else when the change is implemented. The commitment often hinges on people's perceptions of possible benefits.

(5) Control the Process. Now that the project has been designed and implemented, the actual degree or level of improvement must be documented and compared to the benchmark established early in the process. Using the new measurements, it is then possible to compare them to the benchmark and the predetermined objective or goal. This allows for an assessment of progress made and the identification of improvements yet to be made.

As was initially stated, this is a process that should lead to continuous improvement. The assessment provides a roadmap for what needs to be done. The team must then revisit all of the previous steps that are applicable for the situation they seek to remedy. Perhaps it means returning to the brainstorming phase or to the task of determining measures that actually measure the performance of the task under consideration.

\section{CONCLUSION}

While all public transit modes are subject to regulation to ensure the safety of the public, it is the responsibility of the individual public transit authority to ensure the safety and security of all its affected publics, passengers and employees, using a comprehensive process to ensure that the plant, equipment, and environs are as hazard free as possible. Public transit systems continually strive to ensure that incidents on and in the immediate vicinity of the bus are dealt with swiftly 
to minimize the possibility of disruptions and injuries. The added element of uncertainty because of the possibility of deliberate acts of sabotage or terrorism makes this responsibility even more essential.

At the present time, the smaller public transit authorities have not received the level of guidance and training that has been available to the largest transit authorities. This does not minimize the responsibility that each transit authority has to develop and implement a process that will lead to a collaborative effort to identify improvement opportunities and implement improvement programs to ensure the safety and security of all involved. The scarcity of personnel and financial resources makes it more important to integrate the suggested process into the normal managerial and operational requirements. By the very nature of the process, this also ensures that communication between riders, drivers, maintenance and security personnel, and management flows freely, resulting in everyone being informed and being an active participant in ensuring that safety and security are a top priority.

An added advantage of adopting a transparent, integrative process such as the one suggested in this study is that all parties are involved in and aware of the establishment of safety and security initiatives. Initiatives can be those revealed as a part of the continuous improvement efforts internal to the transit entity or they can be initiatives that have been mandated through governmental entities such as the Department of Transportation Security, Federal Transit Administration, or the Department of Transportation. 


\section{APPENDIX A: DIRECTOR SURVEY}

The following questions are designed to provide a picture of the current procedures, activities, and measures that are being used by the transit authority in their on-going efforts to provide the highest levels of safety and security for their employees and passengers. It is also designed to determine the procedures in place to provide security for the equipment and facilities of the transit authority.

This is part of an ongoing project to provide transit authorities with usable Security Enhancement Process documentation that can be used as a blueprint for their own on-going safety and security efforts.

Part I: General Information

1. What is the title of the person responsible for the current safety program?

2. Is this responsibility full time? part time?

3. What is the title of the person responsible for compliance?

4. Is this responsibility full time? part time?

5. What is the title of the person responsible for the current security program?

6. Is this responsibility full time? part time?

The following questions refer to the emphasis placed on safety procedures. All questions are ranked from I (No Emphasis) to 5 (Much Emphasis).

\begin{tabular}{|c|c|c|c|c|c|}
\hline & $\begin{array}{c}\text { No } \\
\text { Emphasis }\end{array}$ & $\begin{array}{c}\text { Slight } \\
\text { Emphasis }\end{array}$ & $\begin{array}{l}\text { Average } \\
\text { Emphasis }\end{array}$ & $\begin{array}{c}\text { Some } \\
\text { Emphasis }\end{array}$ & $\begin{array}{c}\text { Much } \\
\text { Emphasis }\end{array}$ \\
\hline 7. Employee training & 1 & 2 & 3 & 4 & 5 \\
\hline 8. Use of maintenance logs & 1 & 2 & 3 & 4 & 5 \\
\hline 9. On-board cameras & 1 & 2 & 3 & 4 & 5 \\
\hline 10, Facility cameras & 1 & 2 & 3 & 4 & 5 \\
\hline $\begin{array}{l}\text { 11. On-board communication } \\
\text { capability }\end{array}$ & 1 & 2 & 3 & 4 & 5 \\
\hline 12. On-board security guards & 1 & 2 & 3 & 4 & 5 \\
\hline 13. Lobby security & 1 & 2 & 3 & 4. & 5 \\
\hline 14. Third party security company & 1 & 2 & 3 & 4 & 5 \\
\hline 15. Procedures manual & 1 & 2 & 3 & 4 & 5 \\
\hline $\begin{array}{l}\text { 16. Established security standards } \\
\text { or goals }\end{array}$ & 1 & 2 & 3 & 4 & 5 \\
\hline 17. Employee identification system & 1 & 2 & 3 & 4 & 5 \\
\hline 18. Restricted access to equipment & 1 & 2 & 3 & 4 & 5 \\
\hline 19. Safety meetings with employees & 1 & 2 & 3 & 4 & 5 \\
\hline 20. Garage and parking area & 1 & 2 & 3 & 4 & 5 \\
\hline
\end{tabular}

21. What procedures are in place to ensure security?

22. What is the title of the person responsible for handling, storing and reusing the films used in video cameras?

23. How many hours are the films maintained before being reused? 
The following questions refer to how record keeping is accomplished. All questions are ranked from I (Nol Recorded) to 5 (Always Recorded)

\begin{tabular}{lccccc}
\hline & $\begin{array}{c}\text { Not } \\
\text { Recorded }\end{array}$ & $\begin{array}{c}\text { Sometimes } \\
\text { Recorded }\end{array}$ & $\begin{array}{c}\text { Average } \\
\text { Recorded }\end{array}$ & $\begin{array}{c}\text { Usually } \\
\text { Recorded }\end{array}$ & $\begin{array}{l}\text { Always } \\
\text { Recorded }\end{array}$ \\
\hline 24. Incident Reports & 1 & 2 & 3 & 4 & 5 \\
25. Accidents & 1 & 2 & 3 & 4 & 5 \\
26. Injuries & 1 & 2 & 3 & 4 & 5 \\
27. Cost of Accidents & 1 & 2 & 3 & 4 & 5 \\
\hline
\end{tabular}

The following questions refer to how the records are used. Please check all appropriate boxes for each type of record.

\begin{tabular}{lcccc}
\hline & Not Used & Track Trends & $\begin{array}{c}\text { Basis for } \\
\text { Basis for Changes in } \\
\text { Existing Procedures }\end{array}$ & $\begin{array}{c}\text { Development of New } \\
\text { Procedures }\end{array}$ \\
\hline $\begin{array}{l}\text { 28. Incident Reports } \\
\text { 29. Accidents }\end{array}$ & 1 & 2 & 3 & 4 \\
30. Injuries & 1 & 2 & 3 & 4 \\
31. Cost of Accidents & 1 & 2 & 3 & 4 \\
\hline
\end{tabular}

The following questions refer to the bus driver hiring processes. All questions are ranked from 1 (Not Used) to 5 (Always Used).

\begin{tabular}{|c|c|c|c|c|c|}
\hline & $\begin{array}{l}\text { Not } \\
\text { Used }\end{array}$ & $\begin{array}{c}\text { Sometimes } \\
\text { Used }\end{array}$ & Used & $\begin{array}{c}\text { Almost } \\
\text { Always } \\
\text { Used }\end{array}$ & $\begin{array}{l}\text { Always } \\
\text { Used }\end{array}$ \\
\hline 32. Physical Testing & 1 & 2 & 3 & 4 & 5 \\
\hline 33. Drug Testing & I & 2 & 3 & 4 & 5 \\
\hline 34. Background Checks & 1 & 2 & 3 & 4 & 5 \\
\hline 35. Licensure (CDL) & 1 & 2 & 3 & 4 & 5 \\
\hline 36. Initial Training After Hire & t & 2 & 3 & 4 & 5 \\
\hline 37. Periodic Training After Hire & 1 & 2 & 3 & 4 & 5 \\
\hline
\end{tabular}




\section{APPENDIX B: RIDER SURVEY}

\section{Part 1: General Information}

Bus Route

Time am pm

1. In a week, how many times do you ride the bus?

$\begin{array}{llll}\text { It to } 4 & 5 \text { to } 7 & 8 \text { to } 14 & 15 \text { or More } \\ \text { Work } & \text { School } & \text { Shopping } & \text { Social } \\ \text { Male } & \text { Female } & & \\ \text { Under 21 } & 22-30 & 31-45 & 46-60\end{array}$

Over 60

2. Why do you use the bus?

3. Are you

4. What is your age?

5. In the future do you think your usage of the bus will

Decrease Stay Same Increase

Part 2: Please answer the following questions about your experiences riding the bus. All the questions are ranked from 1 (Very Concerned) to 5 (Very Unconcerned);

\begin{tabular}{|c|c|c|c|c|c|}
\hline & $\begin{array}{c}\text { Very } \\
\text { Concerned }\end{array}$ & Concerned & Neutral & Unconcerned & $\begin{array}{c}\text { Very } \\
\text { Unconcerned }\end{array}$ \\
\hline 6. Are you concerned about safety? & 1 & 2 & 3 & 4 & 5 \\
\hline 7. Are you concerned about security? & 1 & 2 & 3 & 4 & 5 \\
\hline $\begin{array}{l}\text { 8. Does the driver appear to be concerned } \\
\text { about your safety? }\end{array}$ & 1 & 2 & 3 & 4 & 5 \\
\hline $\begin{array}{l}\text { 9. Does the driver appear to be concerned } \\
\text { about your security? }\end{array}$ & 1 & 2 & 3 & 4 & 5 \\
\hline
\end{tabular}

10. What security devices are in place on the bus for your protection?

11. What safety equipment is on the bus for your safety?

12. Does the equipment appear to be well maintained?

No Yes

13. Have you ever been on a bus when an accident occurred?

No

Yes

14, If you answered yes to number 13 , how do you feel the driver handled the situation?
Very Unprofessionally
Unprofessionally
Neutral
Professionally
Very Professionally

15. Have you ever been on a bus when a disturbance occurred?

No

Yes

16. If you answered yes to number 15, how do you feel the driver handled the situation?
Very Unprofessionally
Unprofessionally
Neutral
Professionally
Very Professionally 


\section{APPENDIX C: DRIVER SURVEY}

The objective of this brief survey is to provide a picture of the current activities and responsibilities of the transit bus operator. Thank you for participating in the survey,

\section{Part 1: General Information}

1. Is there an existing Manual of Policies and Procedures?

2. If you answered yes to 1 , are you familiar with the contents?

3. Was familiarization with the policies and procedures part of your initial orientation and training?

4. How long was your initial training period (in weeks)?

5. Do you participate in an on-going training program?

6. If you answered yes to 3 , how frequently does training take place?

$\begin{array}{ll}\text { No } & \text { Yes Do Not Know } \\ \text { No } & \text { Yes } \\ \text { No } & \text { Yes }\end{array}$

No Yes

Daily Weekly Monthly Other

Part 2: The following questions refer to the emphasis placed on aspects of training that you received after being hired by the transit authority. All the questions are ranked from 1 (No Emphasis) to 5 (Much Emphasis).

\begin{tabular}{lccccc}
\hline & $\begin{array}{c}\text { No } \\
\text { Empliasis }\end{array}$ & $\begin{array}{c}\text { Slight } \\
\text { Emphasis }\end{array}$ & $\begin{array}{c}\text { Some } \\
\text { Neutral }\end{array}$ & $\begin{array}{c}\text { Much } \\
\text { Emphasis } \\
\text { Emphasis }\end{array}$ \\
$\begin{array}{l}\text { 7. Policies and Procedures } \\
\text { 8. Equipment Operation }\end{array}$ & 1 & 2 & 3 & 4 & 5 \\
9. Security & 1 & 2 & 3 & 4 & 5 \\
10. Safety & 1 & 2 & 3 & 4 & 5 \\
11. Rider Relations & 1 & 2 & 3 & 4 & 5 \\
12. Incident Recognition & 1 & 2 & 3 & 4 & 5 \\
13. Incident Handling & 1 & 2 & 3 & 4 & 5 \\
14. Incident Reporting & 1 & 2 & 3 & 4 & 5 \\
15. Practice Driving with Experienced Driver & 1 & 2 & 3 & 4 & 5 \\
16. Other (please list) & 1 & 2 & 3 & 4 & 5 \\
\hline
\end{tabular}


Part 3: The following questions refer to your feelings about the adequacy of aspects of trair you received after being hired by the transit authority. All the questions are ranked from 1 Inadequate) to 5 (Very Adequate).

\begin{tabular}{lcccc}
\hline & $\begin{array}{c}\text { Very } \\
\text { Inadequate }\end{array}$ & Inadequate & Neutral & Adequate \\
\hline 17. Policies and procedures & 1 & 2 & 3 & 4 \\
$\begin{array}{l}\text { 18. Equipment operation } \\
\text { 19. Security }\end{array}$ & 1 & 2 & 3 & 4 \\
20. Safety & 1 & 2 & 3 & 4 \\
21. Rider Relations & 1 & 2 & 3 & 4 \\
22. Incident Recognition & 1 & 2 & 3 & 4 \\
23. Incident Handling & 1 & 2 & 3 & 4 \\
24. Incident Reporting & 1 & 2 & 3 & 4 \\
25. Practice Driving with Experienced Driver & 1 & 2 & 3 & 4 \\
26. Other (please list) & 1 & 2 & 3 & 4 \\
\hline
\end{tabular}

Part 4: Overall Assessment.

\begin{tabular}{|c|c|c|c|c|}
\hline $\begin{array}{l}27 \text {. How would you rate the training that } \\
\text { you received? }\end{array}$ & Not Useful & $\begin{array}{l}\text { Not Very } \\
\text { Useful }\end{array}$ & Adequate & $\begin{array}{l}\text { Slightly } \\
\text { Useful }\end{array}$ \\
\hline 28. How would you rate the level of safety? & Very Low & Low & Adequate & High \\
\hline 28. How would you rate the level of security? & Very Low & Low & Adequate & High \\
\hline
\end{tabular}

30. What other training would you find useful?

31. What safety procedures do you perform? Pre-shift equipment check Incident prevention Operate the bus according to safely requirements

32. What security procedures do you perform? Awareness and reporting of unusual activities Inspecting inside and outside of vehicle 


\section{References}

Benedetto, A.R. "Adapting Manufacturing-Based Six Sigma Methodology to the Service Environment of a Radiology Film Library." Journal of Healthcare Management 48 (4), (2002): 263-280.

Brown, S.W. and T.A. Swartz. “A Gap Analysis of Professional Service Quality.” Journal of Marketing 53 (April), (1989): 92-98.

Candido, C.J. F. and D. S. Morris. “Charting Service Quality Gaps.” Total Quality Management 11 (July), (2000): 463-473.

Cannon, J. and W. Perreault. "Buyer-seller Relationships in Business Markets." Journal of Marketing Research (32), (1999): 430-460.

Crosby, L. and S. Johnson. “Customer Relationship Management.” Marketing Management 9 (3), (2000): 4-6.

Day, George. "Creating a Superior Customer-Relating Capability." MIT Sloan Management Review 44 (3), (2003): 77-83.

Deighton, J. “The Future of Interactive Marketing.” Harvard Business Review 74 (6), (1998): 151-160.

Esper, T.L. and L.R. Williams. "The Value of Collaborative Transportation Management (CTM): Its Relationship to CPFR and Information Technology." Transportation Journal 42 (4), (2003):55 - 65.

Fisher, M. "What is the Right Supply Chain for Your Product?" Harvard Business Review (MarchApril), (1997): 105-116.

Harry, M.J. and R. Schroeder. Six Sigma: The Breakthrough Management Strategy Revolutionizing the World's Top Corporations. Doubleday, New York, 2000.

Headley, D.E. and B. Choi. "Achieving Service Quality Through Gap Analysis and a Basic Statistical Approach.” The Journal of Services Marketing 6 (Winter), (1992): 5-15.

Hoerl, R. and R.D. Snee. Statistical Thinking: Improving Business Performance. Duxbury Press, Pacific Grove, CA, 2002.

Kelly, S. Data Warehousing in Action. Wiley, New York, 1997.

Larsen, B. and T. Haversjo. "The Year 2000 Problem of ISO 9000: Will the Quality Standards Survive the Proposed 2000 Revision?” The TQM Magazine 12, (2000): 226-236.

Normann, R and R. Ramirez. "From Value Chain to Value Constellation: Designing Interactive Strategy." Harvard Business Review 71, (1993): 65-77.

Parasuraman, A., V. Zeithaml, and L. Berry. "A Conceptual Model of Service Quality and Its Implications for Future Research.” Journal of Marketing 49 (Fall), (1985): 41-50. 
Parasuraman, A., V. Zeithaml, and L. Berry. "SERVQUAL: A Multiple Item Scale for Measuring Customer Perceptions of Service Quality.” Journal of Retailing 64 (Spring), (1988): $12-40$.

Peppers, D. and M. Rogers. The One To One Future. Piatkus, London, 1993.

Sebastianelli, R. and N. Tamimi. "Understanding the Obstacles to TQM Success." The Quality Management Journal 10 (3), (2003): 45-56.

Seybold, P. "Get Inside the Lives of Your Customers." Harvard Business Review 79, (2001): 8091.

Taghaboni-Dutta, F and K. Moreland. "Using Six-Sigma to Improve Loan Portfolio Performance." The Journal of American Academy of Business 5 (1/2), (2004): 15-20.

Thomas, K. "Conflict and Negotiation Processes in Organizations." in Dunnette, M. and L. Hough eds. Handbook of Industrial and Organizational Psychology, Consulting Psychologists Press, Inc., Palo Alto, CA (1992).

United States Department of Transportation. "American Public is Concerned about National Security Issues but Satisfied with Federal Government's Efforts.” Omnistats, (March, 2), (2002): 1-2.

U.S. Department of Transportation. "Top 20 Security Program Action Items for Transit Agencies.” http://transit-safety.volpe.dot.gov/ security/SecurityInitiatives/ Top20/ default.asp, accessed 9/29/2004.

U.S. Department of Transportation. "Employee Guide to System Security - Bus Operations." http://transit-safety.volpe.dot.gov/Security/Security Initiatives/EmployeeGuide/BUS/, accessed 9/29/2004.

Wycoff, D. "New Tools for Achieving Service Quality.” Cornell Hotel and Restaurant Administration Quarterly 25 (November), (1984): 78-91; reprinted 42 (August) (2001): 25-38.

Kathryn Dobie is the UPS Endowed Chair of Logistics at North Carolina A\&T State University. She received her Ph.D. from the University of Memphis and holds the CPIM, CPM, and CTL professional certifications. Her research interests center around the impact of environmental changes on transportation and supply chain operations.

Rhonda L. Hensley is an assistant professor at North Carolina A\&T State University. Her research interests are in the area of the effects of new technologies on operations management. 